\title{
Qualitative Perspectives on the English Language Content Knowledge and Methods on Communicative Language Proficiency, Implications for Succeeding in the IELTS
}

\author{
Ali Al-Bulushi \\ Sultan Qaboos University, Oman \\ Ali Al-Issa \\ Sultan Qaboos University, Oman \\ Rima Al-Zadjali \\ Gulf College, Oman
}

\section{Introduction}

Several authors highlighted the centrality and fundamentality of communicative language proficiency (CLP) for English teachers today (Al-Mekhlafi, 2007; Cullen 1994; de Lima, 2001; Fahmy \& Bilton, 1992; Tuzel \&Akcan, 2009)and considered it as the "main goal" (Cullen, 1994), "backbone" (Al-Mekhlafi, 2007), and a "prerequisite" (Tuzel \& Akcan, 2009) of any English language teacher education program (Cullen, 1994) to meet the current serious professional and social challenges, changes, demands, and expectations, despite the complexity of the process, especially in contexts where English is a foreign language (EFL), like the Arab World, for example (Al-Mekhlafi, 2007).

A lack of CLP is additionally an impediment to those teachers' professional growth and a characteristic of inefficient and unqualified English language teachers (de Lima, 2001; Komur, 2010; Richards, 2008). CLP here is associated with knowledge about the target language (i.e. declarative knowledge) and demonstrating ability to do things using that knowledge (i.e. procedural knowledge) (Pasternak \& Bailey, 2004) in numerous contexts governed by different interactional conventions, functions, and rules (Bachman \& Palmer, 1996).Stern (1983) considered CLP as involving “. . . mastery of the linguistic, cognitive, affective and sociocultural meanings, expressed by language forms" 
(p. 341). However, Stern (1983) stressed achieving creativity in language use through paying maximum attention to communication and minimum attention to form.

Al-Gahtani and Reover (2013), on the other hand, included explicit details about the four skills and mentioned grammar and vocabulary, while had not made any reference to aspects like sociocultural knowledge. They defined language CLP as the demonstration of control over grammatical structure, breadth and depth of vocabulary knowledge, and ability to read efficiently, write clearly, listen precisely, and speak fluently and accurately.

\section{CLP in Initial ELT Education Programs}

Initial English language teacher education programs were held responsible for not showing sensitivity towards supporting Non-Native English Speaking Teachers (NNESTs) to use the target language proficiently and confidently (Al-Mekhlafi, 2007; Centinavci\&Yavuz, 2010; Coskun\&Daloglu, 2010; Fahmy\&Bilton, 1992; Hadjioannou\& Hutchinson, 2010; Salihoglu, 2012; Tuzel\&Akcan, 2009). These researchers further held their respective programs accountable for taking into account the demands of their Student Teachers (STs) and thus paying minimal attention to helping them to improve their command of English. They ascribed this to the content knowledge and methods and called for re-evaluating and restructuring their courses to comply with the requirements of the profession.de Lima (2001) asserted that the content and processes and methods of the ELT teacher education programs are a source of concern due to the fact that "only a few teacher-training courses are capable of achieving the objective of improving the communicative command of the target language" (p. 143).

Cheng, Ren and Wang (2003) stressed the need of ELT STs for more training in CLP than in other areas like linguistics, culture and literature, for example, which develop their theoretical linguistic knowledge rather than their communicative abilities. Morain (1990) viewed "required language courses", "courses in the content area" and "courses in pedagogy" (p. 149) amongst others as responsible for educating ELT STs.

\section{Literature Review}

Developing STs' CLP has received considerable attention from numerous authors over the past few decades. In his pursuit to evaluate a Turkish ELT teacher education program, Uzun (2016) collected data from 90 STs using a questionnaire and 15 interviews. Results indicated that Oral Communication Skills, Effective Communication Skills, Listening and Pronunciation, Vocabulary Acquisition, Contextual Grammar and Linguistics 1 and 2 received a relatively high mean as they contributed to STs' personal development, professional development and use of the received knowledge during active teaching. Furthermore, 10 STs thought 
that the English Literature and Poetry Analysis courses were ineffective due to their contents, which offered very little and had little link to their classroom teaching. In addition, $53 \%$ stated that the course teachers contributed more to their development, while $46 \%$ commented that both course teachers and course content contributed equally to their development.

Salihoglu (2012) explored the beliefs of English language STs and their instructors on the effectiveness of an educational program at a Turkish university. Data was collected through two similar questionnaires, a focus group and semi-structured interviews with three instructors. The results of the STs and instructors' questionnaires revealed very similar beliefs about the effective and ineffective components of the program. The findings suggested that even though one third of the STs were satisfied with the program, adequate training in the target language was found to be neglected.

Centinavci and Yavuz (2010) collected data through questionnaires distributed to 144 ELT STs in Turkey. The two authors found that STs suffered from deterioration or no positive change in their grammatical and lexical knowledge in English due to the existing problems of teaching practices and curriculum. The two authors stressed the importance of providing as many language practice and interaction opportunities as possible for NNEST STs.

Within the Turkish context, Coskun and Daloglu (2010) collected data from 55 STs by means of questionnaires. They further interviewed 10 out of those 55 STs and 3 faculty members about the program content knowledge and methods. The two researchers found that some STs complained about the overuse of presentations by some lecturers and a considerable amount of memorization involved in the courses. They also found that lecturing was more or less the dominant mode of delivering courses. Furthermore, the three faculty members agreed that the program focused more on developing STs' pedagogic competence neglecting their linguistic competence. The faculty members also thought that the number of courses allocated for improving STs' linguistic competence had been insufficient and should be increased.

In their qualitative case study, which included 31 pre-service English teachers in an elementary education certification program, Hadjioannou and Hutchinson (2010) found that STs today enter certification programs with significant gaps in their formal grammar knowledge, which is an impediment to the STs and the learners they will be teaching in their classrooms. The two authors stressed the importance of incorporating some kind of explicit grammar instruction in the teacher education program coupled with an application component so that STs have a firm foundation in basic grammatical knowledge and understand and recognize the importance of this aspect for their effectiveness as classroom teachers. 
Tuzel and Akcan (2009) further investigated the challenges NNETS STs experience in their target language use when they do their practicum in actual language classrooms. Data were collected from five STs through the classroom observations, feedback sessions, semi-structured interviews, retrospective protocols and discussion meetings. The two authors found that STs encountered difficulties in conveying the meaning of a word to students in the target language, certain English grammatical structures, using English for managing classroom and modifying of the oral target language to the students' level of organizing instruction. The two researchers recommended integrating language refreshment sessions in the curriculum and increasing the number of the speaking classes designed to improve the oral skills of the language teachers as possible solutions. Peacock (2009) collected data from program tutors and students at City University Hong Kong about the strengths and weaknesses of the program and ways of improving it by means of six different methods. He interviewed 101 students, collected questionnaires from 65 STs, interviewed eight teachers and analyzed different documents. He found that more than half of the STs who completed the questionnaire thought that the program did not give them adequate training in English. As far as the teachers' interviews were concerned, some of them said that focus on the language side was insufficient and that more emphasis on language awareness was needed. Moreover, 32\% of the students said in their essays that the program should give more attention to knowledge of and proficiency in English. Sixty-six percent of the students were critical of the lecturing mode adopted by some lecturers, which did not stimulate real learning. Evaluation of course materials showed that linguistic competence made up only $18 \%$ of the program, mostly in year 1, which makes the program unbalanced and which contradicts the teachers' statements.

In a study from the Middle East, Al-Mekhlafi (2007) investigated the perceptions of 143 STs at an Emirati university about the necessary specialized competencies they have acquired during their ELT program by means of a questionnaire. Results indicated that while participants acquired "basic level competencies", they did not acquire "higher level competencies" in order to be able to carry out their duties at schools in an effective manner. The former refers to "the ability to use the language in highly predictable and familiar situations". By contrast, the latter is associated with "the ability to use the language fluently" to accomplish "a wide range of communicative tasks related to familiar or new subject matters" and organize one's spoken and written thoughts "in appropriately coherent and cohesive discourse" (p. $11)$.

Al-Mekhlafi (2007) also found that the majority of STs believed that the courses related to developing their "specialist competencies" were insufficient. Specialist competencies refer to the ability to use the four language skills communicatively and "to be linguistically, culturally, and literarily proficiently in the target language" (p. 11). Such courses, which occupied around $32 \%$ of the total 
composition of the program, are language skills courses, grammar and linguistic courses and literature and cultural courses. The author hence recommended reconsidering the quality and quantity of the courses through restructuring the program taking into account "the overall distribution of the courses" and "the teaching strategies" (p. 21).

In their case study about SQU ELT STs, Fahmy and Bilton (1992) collected the answers of 74 STs about the planning of an English language teacher education program through questionnaires. STs who were found to have intermediate to highintermediate English language proficiency, considered it extremely important to upgrade their grammar and oral skills. Fahmy and Bilton further found that the participants were unconfident about their language proficiency and that it would influence their performance in the classroom and their students' learning. The participants were found aware of their needs to improve their language proficiency and expressed a desire for more language training. The two writers suggested conducting periodic fact-finding endeavors to help design and structure a more promising program.

\section{The Problem}

English language teachers graduating from Sultan Qaboos University (SQU) - the only national university in Oman - spend 4-5 years at SQU during which they come into contact with different language improvement courses at the Language Centre, content-knowledge courses at the College of Arts and Social Sciences and English-medium educational courses at the College of Education. Such graduates have come under the microscope (Al-Issa, 2005; Fahmy\&Bilton, 1992; Moates, 2006) for the past 25 years or so and have been criticized for lacking sufficient CLP by different officials in different organizations and sectors concerned across the country. As a reaction to this dilemma, the Ministry of Education in Oman has sanctioned a minimum score of Band 6 on the widely and internationally recognized and dominant International English Language Testing System (IELTS) and the threshold of the Test of English as a Foreign Language (TEOFL) on the iBT version. Both tests are considered valid, reliable and the main criteria for accepting English language teachers graduating from any academic institution including SQU as a measure to reflect a minimum threshold level for the CLP. Nonetheless, some fourth-year ELT STs have failed to achieve the specified score.

It is noteworthy that candidates who score Band 6 in the IELTS are considered competent users with generally effective command of the language despite some inaccuracies, inappropriacies and misunderstandings. Such candidates can also use and understand fairly complex language, particularly in familiar situations. 


\section{Rationale}

This qualitative study investigates the perspectives of some ELT STs and faculty members at SQU about the program content knowledge and methods and their implications for succeeding in the IELTS. Many candidates find the IELTS a difficult test and struggle to achieve the aspired band score, where in many cases high stakes for work, for example, rest on it, as it is the case in this study. A close scrutiny of the contents and components of the IELTS and the pertinent literature on the knowledge required to achieve a high band score in the IELTS reveal that candidates are required to demonstrate creative communicative ability about using the target language in different linguistic, cultural and sociocultural contexts. The IELTS places various linguistic, cognitive, affective and sociocultural demands on candidates in terms of possessing theoretical and practical knowledge about the four language skills, grammar, vocabulary and pronunciation. In other words, the academic IELTS expects candidates to possess declarative knowledge and procedural knowledge. In the case of NNETSs, the latter is complex and comprises of basic level competencies and higher level competencies.

A review of the pertinent literature on the ELT teacher education content knowledge and methods has shown that no published research hitherto has pursued such topic. This study aims to redress this gap within the SQU ELT program context through providing a new empirically qualitative perspective. This is particularly important since there has been an evident dearth of research at SQU that examines such an issue.

\section{Method}

\section{Research Questions}

1. What are SQU ELT STs and faculty members' perspectives about the teaching content knowledge in the initial English language teacher education program and its effect on the STs' IELTS band scores?

2. What are SQU ELT STs and faculty members' perspectives about the teaching methods in the initial English language teacher education program and its effect on the STs' IELTS band scores?

3. What implications do the SQU ELT STs and faculty members' perspectives have for succeeding in the IELTS?

Design

This study was driven by a "directed content analysis" approach (Hseih\& Shannon, 2005). It tried to explore the perspectives of some SQU ELT STs and faculty members about the effect of the ELT program content knowledge and methods on the STs' IELTS band score in order to validate and extend the existing theory and enrich the pertinent literature. 


\section{Participants}

This study was part of a large-scale study that investigated SQU Omani English STs' language proficiency and is funded by SQU. Fifty-eight (21 males and 37 females) graduating ELT major education students took the academic IELTS. Six STs agreed to be interviewed after they had taken the exam. They were divided them into three groups: informants who scored below the overall IELTS Band 6, informants who scored Band 6, and those who scored above Band 6 overall (see Table 1). There were two interviewees in each group each of which was interviewed separately.

Table 1 IELTS Scores of the Study Interviews

\begin{tabular}{lccccc}
\hline $\begin{array}{l}\text { ST. } \\
\text { No. }\end{array}$ & Overall Band Score & Listening & Reading & Speaking & Writing \\
\hline 1 & & & & & \\
2 & 7.5 & 7.5 & 8 & 8 & 7 \\
3 & 6.5 & 7 & 7 & 8 & 7 \\
4 & 6 & 5.5 & 6 & 6 & 5.5 \\
5 & 5.5 & 6 & 5.5 & 6 & 5.5 \\
6 & 5.5 & 5 & 5.5 & 6 & 5.5 \\
\hline
\end{tabular}

The STs' study program involved taking courses from three different academic entities at SQU, namely: the Language Centre in the first year and the Department of English Language at College of Arts and Social Studies and College of Education in the subsequent years. Over $70 \%$ of the courses are taught by the English Language Department, covering courses such as Linguistics, Literature, Second Language Acquisition, Semantics, Syntax, Phonology, Phonetics, and Sociolinguistics. The rest were Language Centre courses, university electives, college requirement courses, and College of Education courses. With the exception of the three university elective courses, all the other courses were taught in English. In addition to the six ST, a major source of data came from three full-time faculty members who represented the College of Education and College of Arts and Social Sciences who participated in the teacher education program of the STs. They were selected purposively to inform the investigated research questions (Zhang \& Wildemuth, 2009). Informant \#7 was a Master of Arts holder supervising participants in their teaching practice. Informant \#8 was an experienced Omani Assistant Professor of Applied Linguistics and teaches different Linguistics courses to ELT STs at the College of Arts and Social Sciences. He also used to supervise some STs during their school-based practicum. Informant \#9 is an expatriate experienced Associate Professor of Applied Linguistics and taught different 
language education courses to ELT STs and College of Education postgraduate students. He too supervised STs during their field teaching practice (see Table 2).

He has been at SQU for over five years. The main purpose of interviewing faculty members was to explore their perspectives about the different content knowledge and methods that influence the STs' CLP, and hence, their band scores in the IELTS.

Table 2. Background Information about Research Participants

\begin{tabular}{|c|c|c|c|c|c|c|c|}
\hline № & Role & Gender & & Nationality & Highe & Qualification & Responsibilities \\
\hline 1 & ST & Male & $20-25$ & Omani & Grade & 12 Certificate & Student \\
\hline 2 & ST & Female & $20-25$ & Omani & Grade & 12 Certificate & Student \\
\hline 3 & ST & Male & $20-25$ & Omani & Grade & 12 Certificate & Student \\
\hline 4 & ST & Female & $20-25$ & Omani & Grade & 12 Certificate & Student \\
\hline 5 & ST & Female & $20-25$ & Omani & Grade & 12 Certificate & Student \\
\hline 6 & ST & Male & $20-25$ & Omani & Grade & 12 Certificate & Student \\
\hline 7 & Lecturer & Female & $30-35$ & Omani & M.A. & & $\begin{array}{l}\text { Supervise STs During } \\
\text { Practicum, Participate in } \\
\text { Committees }\end{array}$ \\
\hline 8 & $\begin{array}{l}\text { Assistant } \\
\text { Professor }\end{array}$ & Male & $60-65$ & Omani & Ph.D. & & $\begin{array}{l}\text { Teach Language Courses } \\
\text { at College of Arts and } \\
\text { Social Sciences to ELT } \\
\text { STs, Supervise Students in } \\
\text { Teaching Practice, } \\
\text { Participate in Committees }\end{array}$ \\
\hline 9 & $\begin{array}{l}\text { Associate } \\
\text { Professor }\end{array}$ & Male & $65-70$ & Non-Omani & Ph.D. & & $\begin{array}{l}\text { Teach ELT Specialized } \\
\text { Courses to ELT STs and } \\
\text { Postgraduate Students, } \\
\text { Supervise Students in } \\
\text { Teaching Practice, } \\
\text { Participate in Committees }\end{array}$ \\
\hline
\end{tabular}

\section{Procedures}

After receiving the required formal institutional approval, the potential informants who met the criteria were identified and contacted. Prior to their involvement, each invited informant received a written description of the study's purpose and the procedure, as well as an informed consent form.

After taking the IELTS test, all STs were contacted to schedule the interview. All six interviews were conducted within two weeks' time after the test. The nine informants were asked the same questions, which constituted the semi-structured 
interview. However, the wording was slightly changed to suit the position of the two groups of informants - STs and faculty members. The question was: Which courses do you think may have hindered your progress or facilitated your CLP (or your IELTS score)? However, in the case of the faculties it was phrased as follows: Which courses from the teacher education program do you think could directly influence the CLP level of the student teachers (or their IELTS score)?

\section{Instrument}

The actual interview session varied in length with an average of 15 minutes. Informants were assured of anonymity in any written reports and their responses were to be treated with the strictest confidentiality. The data were presented based on the individual answers of the informants, and were reduced to include only the information relevant to the purpose of the study.

The interview questions together with the purpose of the study were sent to an expert jury of two educationalists in the field to check its validity. The jury's feedback improved the wording of the questions and made them more concise and less directive.

An additional and equally important source of data leading to triangulation is the pertinent literature on the topic under investigation. It attempted to converge and diverge different discourses elicited from the informants and the pertinent literature to help reduce and minimize any biases held by us as researchers, applied linguists and ELT practitioners with longstanding experience and extensive theoretical and practical knowledge about the topic, which enhanced the credibility and validity of the findings (Golafshani, 2003; Shenton, 2004).

The literature additionally guided us to compare the data we collected through interviews with the pertinent theories and models appearing in the sections concerned. This led us to "draw attention to both, to the similarities and differences ... and to carve out diversity as well as similarity" (Palmberger \& Gingrich, 2013).

\section{Analysis}

Our aim was to retest previously formulated theories about the topic. We therefore adopted a deductive approach to qualitative content analysis to answer the first research question (Elo \& Kyngas, 2008). We divided our data analysis into two phases. In the first phase we immersed ourselves in the data and read it through several times to familiarize ourselves and look for certain key words/terms, phrases, sentences and paragraphs, which represented characteristics of the content knowledge and teaching methods since ELT teacher training and education programs are usually evaluated according to the efficiency and method of the content offered and since this was the focus of the pertinent literature, which 
guided our deductive coding scheme (Hsieh \& Shannon, 2005). We extracted all the text from the participants' statements. Following a manifest qualitative content analysis approach, we read the data and took down headings in the margins that related to curriculum and instruction using the text highlighting and review facility in Microsoft Office Word. We designed two "structured categorization matrix" tables (Elo \& Kyngas, 2007) - one for content knowledge and the other one for teaching methods. We divided each one into two main columns: One for the participants' statements and the other one for the pertinent literature. Next, we began to fill the first column of our two tables with subcategories pertinent to each category. Interestingly, while none of the informants directly and explicitly labeled some of the sub-categories, the concepts, descriptions and examples used by the informants resembled those provided by the pertinent literature.

It is worth noting that we found an additional sub-category in the interview data pertinent to the content knowledge, which did not fit the categorization frame in Table 3. The sub-category was related to missing courses, which were pertinent to language proficiency improvement and which we thought was irrelevant to the findings of the study. However, when we consulted the literature reviewed earlier, we could see reference made to the strong relationship between declarative knowledge and procedural knowledge.

In the second coding phase of our data analysis, we turned our attention to the pertinent literature. The currently available literature on the topic helped us focus our research questions to include content knowledge and teaching methods as the two main categories of interest and the strong relationship between them (Hsieh \& Shannon 2005). It further helped us to compare and contrast the data we obtained from the participants' statements with the pertinent literature and to look for similarities and differences, presences and absences, agreements and disagreements, and conflicts and harmony between the two sets of data to allow for theory extension. We filled each of the two columns of the tables with the corresponding data we came across from the literature as we reviewed the relevant literature (see Table 3 and Table 4).

We followed Elo and Kyngas's (2008) advice pertaining testing categories, concepts and hypotheses. We only chose from the data the categories that fit our structured matrix of analysis. However, aspects like non-language/education courses additionally emerged from the data, which did not fit the categorization frame, and hence, could not be coded. However, after consulting the reviewed literature we could see the attention these Arabic-medium courses give to pedagogical knowledge improvement at the expense of linguistic knowledge development, which reduced STs' chances of gaining additional exposure to and practicing of the target language. 
Table 3 Data Coding to Structured Categorization Matrix about the Content Knowledge

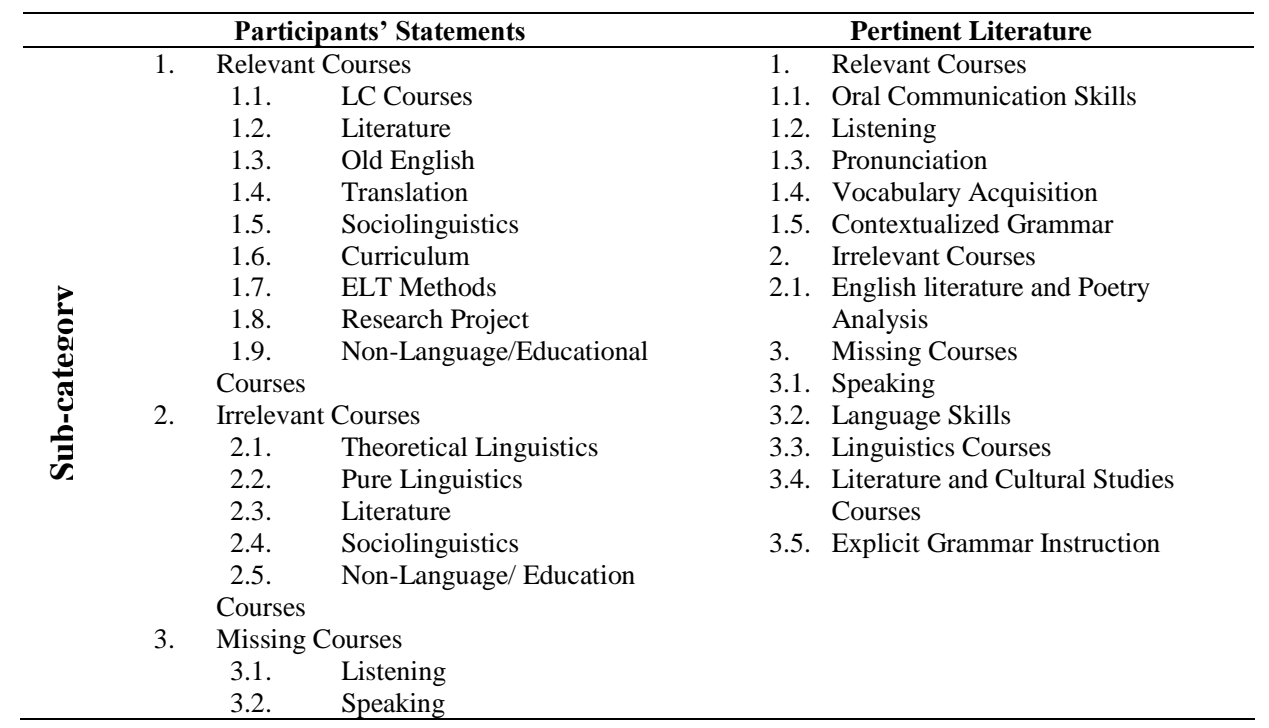

Table 4 .Data Coding to Structured Categorization Matrix about the Teaching Methods

\begin{tabular}{|c|c|c|}
\hline & Participants' Statements & Pertinent Literature \\
\hline 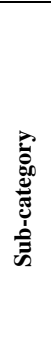 & 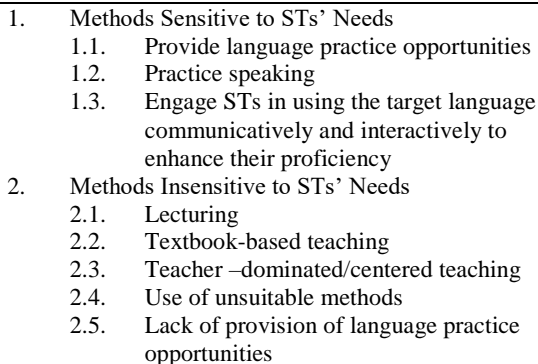 & $\begin{array}{ll}\text { 2. } & \text { Methods Insensitive to STs' Needs } \\
\text { 2.1. } & \text { Presentations } \\
\text { 2.2. } & \text { Lecturing } \\
\text { 2.3. } & \text { Memorization }\end{array}$ \\
\hline
\end{tabular}

\section{Findings}

\section{Content Knowledge}

Informant \#1 praised all the writing courses he took at the LC. He also believed that the Reading course and Literature course offered at the Department of English Language contributed to his higher level competencies.

Actually most of them contributed to my score now, because in the reading passages, for example, I've had something about literature. So, if I didn't study literature during my period at SQU, I would find some difficulty in understanding 
the language of the text. I also remember there was a passage about Suggestopedia and I had a previous idea about the topic before reading it. I also had five courses in writing and they definitely contributed to improving my writing skill.

Similarly, Informant \#5 made a specific reference to writing. He thought that the writing course he took at the LC helped him improve his basic and higher level competencies.

Actually, there are many courses. I can't say one course, because some courses have helped you. For example, I have taken three courses of writing; from writing sentences until writing a term paper or a research project. There were about four or five courses. We cannot say only one course.

Informant \#2 further had positive perspectives about the LC courses due to their intensive nature and contribution to her basic level competencies. She also felt that the Critical Reading course helped her enhance her higher level competencies.

The courses that facilitated my language proficiency were I think the courses in the Language Centre because they were intensive exposure to the language, grammar, reading, writing, and even in the Department of English, some of the courses like Grammar and Reading. The Critical Reading course also had a great effect. We were taught how to read critically and not to accept everything blindly.

She added that some of the other non-English language training courses impacted her higher level competencies, as she could incorporate the knowledge offered in those courses into her teaching knowledge.

Some of the educational courses also helped, but not all of them such as the ELT Methods courses and, I think, the Educational System. I mean I learned a lot from the ELT Methods courses and the Education Systems. I could incorporate what I learnt into my current experience.

Informant \#4 attributed her success in the IELTS to the two literature courses she had taken at the Department of English Language. She believed that reading novels affected her higher level competencies.

Actually the most useful courses I have taken from the Department of English. They have literature and it was very helpful. I read novels, so it helped improve my language proficiency when I took the IELTS and in reading and writing as well. So, I know how to write different structures while I'm reading different novels. Actually, I have taken two literature courses. They are very helpful and I'm very interested in literature. 
She then went on to talk about other courses that she felt improved her higher level competencies and helped her achieve the required band score in the IELTS. "Actually, Reading courses in the Department of English, the elective Reading course is very helpful. Also, I have taken the Research Project course. I think it has been very helpful in writing; how to write".

Informant \#5 thought that the "Old English" course was a little helpful as it helped him improve his higher level competencies.

I took many courses as elective in addition I have taken many as obligatory courses. However, we take from the track that the students will choose what they like so that the benefit will be more than that. Actually, the only thing that I found useful from that course, was me as an English specialist, I know that the old English language is different than the new language or the modern language, so that I get the chance to be introduced to the old language. Now I have an idea about the old language and the new language. It contributed to my language competence a little bit. For me as an English learner, I found it enriched my knowledge a bit.

What we say the meta-linguistic.

Informant \#3 gave more specific examples of courses he took at the College of Education that reflected positively on his higher level competencies and helped him achieve band score 6 in the IELTS.

In the ELT Methods you know how to teach and what are the different ways of teaching. They helped me to be focused in my grammar, teach us how to stand in the classroom and how to say our sentences correctly. That is very helpful, because in the Department of English we just speak and we didn't pay attention to our grammar. Just speak to deliver our messages; to be understandable more. We have one Curriculum course. We use about different methods and how to apply it in the classroom. I found it very useful and tried to apply it in the classroom. The courses all of them are useful.

Like most of the STs, Informant \#7 had positive ideas about all the courses offered at the LC and Department of English Language and felt that some of them could aid procedural knowledge and influence the development of basic level competencies and higher level competencies.

All LANC courses and language skills courses from ENGL directly lead to development as this is their purpose. Other courses could indirectly help. For example, Literature and Translation courses aid the expansion of vocabulary and style and Linguistics courses aid structural accuracy and probably language awareness. Sociolinguistics leads to better communicative awareness. 
Interestingly, while Informant \#7 mentioned the Literature and Linguistics courses as indirectly aiding declarative knowledge, Informant \#8 was critical of the inclusion of Literature and Theoretical Linguistics and strongly believed they had no impact on any of the STs' procedural knowledge, and hence hindered their achievement of the aspired band score in the IELTS.

In my view the Theoretical Linguistics courses should not be in their syllabus. The students do not have time to waste. The same is true with Shakespeare and courses like that. The student teachers do not have the luxury to study subjects that contribute towards their profession. You can grab their course plan and based on my comments you can conclude which ones are those. The course outlines and the approach is not geared towards focusing on the practical needs of the student teachers. The courses must be checked and seen by competent authorities to focus on the students' needs.

Informant \#1 largely corroborated Informant \#8's statement and contradicts Informant \#7's statement. He was also critical of the Literature course. He was additionally critical of the Sociolinguistics course. He believed they contributed to his declarative knowledge, but not to his procedural knowledge, as they lacked a practical and interactive nature.

I've taken two electives in English. They were mainly for specialists, Pure Literature and Sociolinguistics, but they didn't contribute that much to my score in the IELTS and my level now, but in terms of language you find new words, new expressions and the structure of the articles you read. They're good, but I don't think they directly contribute to your practical knowledge.

Informant \#5 also largely complemented the last two informants and thought that the Literature course was irrelevant due to its theoretical nature, and hence, its failure to contribute to developing the STs' procedural knowledge. "There are some courses I found pointless. We are studying about, for example, Literature. Those courses are for the language itself, as Omani, I couldn't find it as much benefit from it".

Informant \#6, who scored 5.5 in the IELTS Listening and Speaking components, was also critical of the absence of a Listening course at the Department of English Language and believed it aided speaking as a productive skill.

There is another skill which is neglected here at SQU; listening. We only took listening in the LC. When we go the Department of English, there is no course in listening. There isn't any focus on listening and if we want to listen to improve our speaking, we do it on ourselves. Here at the university there are only two courses with listening at the Language Centre. 
Interestingly, and like Informant \#1, but contrary to the rest of the STs, Informant \#6 believed non-language courses do not serve achieving the required band score in the IELTS due to their unrelated declarative knowledge to the IELTS.

I think the non-language courses I took at SQU don't help with the IELTS because the test is general and each course is very specific on its major and most of them are educational if they are not language courses. They are talking about teaching, how to deal with students and psychology. I think they didn't help with the IELTS.

Informant \#8 then suggested solutions to what he firmly believed to be unsatisfactory content knowledge. He linked STs' language needs and success in language acquisition to exposure to and practice of professional English, which could provide higher level competencies enhancement.

They need more writing, more reading, and short stories. They need more reading in professional journals, which focus on practical aspects of learning, training, and teaching and not on aspects that deal with the theoretical aspects of the M.A. or Ph.D. levels or on controversial theories, which most students fail to understand.

\section{Teaching Methods}

While some of the content knowledge courses received some praise in the last section, this was not the case with most of the teaching methods, which lacked sensitivity towards STs' needs and interests. The informants took a more critical stance with the teaching methods adopted by some of the faculty members. Informant \#1 thought that while some of his teachers were "excellent", as they gave STs the opportunity to interact during the class time others were traditional lecturers, who dominate proceedings and hindered procedural knowledge acquisition and development.

The teacher, the way of explaining, for example, some of them are excellent, they give you a chance to talk, while some lecture for two hours; some of the teachers would like for the whole time to use PowerPoint slides and then it's dark and the voice of the teacher is like monotonous and sometimes you read from the slides and the slides are full of paragraphs. But I remember a doctor in the College of Education and in the slides you would find only words or phrases and all the explanations are based on him. This is my view of using the PowerPoint. I find it a distracter more than like a facilitator, because if you put everything in the slides, the students' attention will go to the slides and they won't listen to you. But if there is a need for you to use the PowerPoint, you can go ahead and use it, but if you can do it without a PowerPoint, do it without it. 
Informant \#4 thought that while the Arabic course was important, the teaching methods adopted by the course instructor impeded her acquisition of knowledge that could help her improve her procedural knowledge development and higher level competencies due to being teacher-dominated and textbook-based. For example, the university requirements, some of them are I think just wasting of time, because it might depend on the teacher. I'll give you an example. It's about the Arabic course. The teacher is not very helpful. I think it's a very important course and I'm very curious to know about Arabic and compare between Arabic and English. But I found the teacher himself not helpful. He said "open this book", "this page", "just read it", "it's just homework". Not giving us information about the rules in Arabic. I want to know the rules in that course and how to compare them with the English language.

Informant \#5 was additionally critical of some of the teachers' teaching methods, who did not show any sensitivity towards the STs' practical language needs and interests. "Actually I found it that it depends on the instructor itself. What the instructor likes will be good. It depends on what he interests in so that students are forced to study that".

Informant \#2 looked at the issue of teaching methods from a more or less similar perspective to Informant \#5 - lacking specific design and overlooking STs' practical needs and interests, which hindered her improvement of the three language competencies. She thought that the methods some of her teachers employed, like tree diagrams, for example, were more suitable for the Science students. "For me, I didn't like the Linguistics courses. I think they hindered my language proficiency because I cannot think in terms of trees. I am an art-oriented student not a scientific-oriented student".

Interestingly, while Informant \#9 emphasized the idea forwarded by the last two informants about the program teachers' lack of sensitivity towards the STs, his analytic perspective was completely different to Informant \#2 and Informant \#5. He thought that while courses offered by the LC that focused on giving the STs the chances to practice the language were relevant, some teachers were not helpful and lacked the desire to make the effort to involve students in developing their CLP through practicing the language.

Obviously those courses that engage students in the negotiation of English language do the most good in this regard. Those that have students reading, writing, speaking and listening in English theoretically enhance our students' level of proficiency. However, few if any of us require our students to write very much, for example. It takes too much time to mark, most colleagues say. Because students in the culture are not in the habit of reading, lecturers, who wish to receive good marks from their students on course evaluations, lessen the reading requirements. But, again, student performance is equal to teacher expectation. I fear our present 
course and program standards are too low. In my professional opinion, we do not expect enough from our students. This is particularly true of expatriate lecturers who wish to have their contracts renewed and also of Omani lecturers who don't want to do the marking.

Informant \#7, who graduated from SQU as an English teacher in 2001 was critical of the pedagogical practices adopted by some of the instructors of one of the courses of the Department of English Language. She felt they did not provide language practice opportunities, and hence, failed to contribute to the STs' higher level competencies.

When students were asked about their feedback on the program, they stated that oral proficiency isn't emphasized or developed in courses. To them, they are given enough and good opportunities to practice the written mode, but they may need additional elements that focus on the spoken mode. In my own experience as a student - I was cohort 2001, in more or less the same program, a pronunciation and speech course - now called Speaking - and ENGL course, was extremely useful to improve my language with lots of assignments involving recording, transcribing, and evaluating components of oral language in different presentational situations. My understanding is that this course no longer involves such elements. This is why I said, the program is good in terms of elements and structure, but there could be some course-level or methodology issues that, if improved, could improve the graduates' level.

\section{Discussion and Conclusion}

In this qualitative study we investigate the perspectives of purposively selected SQU ELT STs and members of the faculty about the content knowledge and methods of the teacher education program and the implications these two aspects have for STs succeeding in the IELTS. The findings indicate that the STs in this study have acquired basic and higher level competencies due to the good range of course offered by the three entities. Good examples are Writing, Literature, Old English, Critical Reading, Sociolinguistics, Research Project, ELT Methods, Curriculum and Education Systems. While these findings partly complement those reported by Uzun (2015), they contradict those reported by Al-Mekhlafi (2007).

Further findings point in the direction of certain courses that equip STs with declarative knowledge such as Theoretical Linguistics, Pure Linguistics, Literature and non-language courses. Such courses have been described by Informant \#1, Informant \#5, Informant \#6 and Informant \#8as irrelevant to STs' CLP development due to their strictly theoretical content, and hence, can impede achieving the aspired band score in the IELTS. These findings are partly in line with those reported by Uzun (2015), but contradict those reported by Peacock (2009) about the ability of the program to give adequate English language training to its participants. 
As far as CLP is concerned, there seems to be a lack of balance in the program structure and composition, which necessitates reconsideration of course distribution which complements the findings reported by Al-Mekhlafi (2007) and Peacock (2009). The aim for this is to create more opportunities for language practice and training, and hence help develop STs' higher level competencies, which complements the findings reported by Fahmy and Bilton (1992), Centinavci and Yavuz (2010), Peacock (2009), Coskun and Dalolglu (2010) and Salihoglu (2012). A good example is the inclusion of a Listening course at the Department of English Language, which is claimed by Informant \#6 to improve speaking. In her quantitative study, which included 50 Chinese college students, Zhang (2009) found a correlation between students' listening and speaking ability, and listening has positive effects on improving her participants' speaking. The author hypothesized that "the students who score higher in listening might obtain higher score in oral English test" (p. 201) like the IELTS speaking test, for example. Furthermore, Bozorgian (2012) investigated the outcome of 1800 Iranian candidates undertaking the IELTS in Iran. He found a significant positive correlation between listening comprehension and the overall CLP of those candidates.

Another relevant example is the Speaking course at the Department of English Language as referred to by Informant \#7. Reference in this informant's statement is made to Conversation Analysis (CA). Zhanglong and Rong (2011) state that while ". . . the ultimate goal of language learning is communication . . . communication refers to verbal communication in the first place" (p. 72). According to Wu (2013), $\mathrm{CA}$ is an effective pedagogical approach to teaching oral English language skills as it is concerned with the micro and macro levels features of discourse. Examples of the former are grammar and intonation, while examples of the latter are power and value systems.

Zhanglong and Rong (2011) also argue that "communicative competence of language includes not only language abilities but also competence beyond language" (p. 72). Wu (2013) reviews literature, which suggests that CA fosters learners' sociolinguistic competence, linguistic competence, discourse competence, and strategic competence, which are interrelated and pivotal aspects of CLP. Wu (2013) depicts that CA maximizes learners' exposure to authentic English, stimulates their interest, impacts their motivation, and transforms their role into researchers. These aspects are relevant for an EFL context, where access to the target language is limited and controlled, and where motivation is strictly driven by criterion-referenced tests, as it is the case in Oman (Al-Issa, 2014). In order to capitalize on CA, ELT programs preparing STs could include it as a separate course or effectively infuse it within existing relevant courses. Although program degrees are usually cramped with many courses, it is worth adding it to facilitate STs' development of CLP. 
In their extensive review of the literature about CA in Applied Linguistics, Sert and Seedhouse (2011) write that CA has important implications for the way the interview in the spoken component of the IELTS is structured in terms of understanding topic organization, turn-taking, sequence, and repair, as directly related to the goals of the test. They also suggest that if CA is applied to investigate classroom interaction in an "informed" manner, it can potentially have significant implications for developing teacher training, teachers' theories and practices, materials, and testing.

It is interesting to note that Literature was judged as relevant by Informant \#4 and Informant \#7 but irrelevant by Informant \#5 and Informant \#8. The role of Literature in influencing foreign language proficiency has been thus highlighted by several scholars (Cruz, 2010; Khatib, Ranjbar \& Fat'hi, 2012; Van, 2009; Yildirim,

2012). Literature, according to these writers, provides exposure to authentic materials, enriches students' cultural knowledge about the target language use, expands students' linguistic repertoire, contributes to the students' CLP, appeals to imagination, enhances creativity, and encourages critical thinking. Furthermore, one of the two text categories found in academic IELTS reading test is literary. This category includes "poems/verse, novels (extracts), short stories and literary articles" (Ying, 2011, p. 9). Ying found that these texts are difficult to understand. Moreover, Sociolinguistics was judged as irrelevant by Informant \#1, but relevant by Informant \#7. Sociolinguistics helps students acquire linguistic and cultural knowledge about the target language and has positive implications for their professional and personal growth (Thiele, 2013). Coupled with prescriptive language teaching method, Sociolinguistics "is a successful method of teaching English" (p. 68) and can help raise STs' awareness about the factors that influence change. Sociolinguistics can additionally provide STs with knowledge and skills “. . to demonstrate what language is used in a particular society and what language codes should be used in a formal English situation" (p. 61).

In addition, Linguistics was criticized for being irrelevant by Informant \#8, while it was praised by Informant \#7 and Informant \#5. Examples of Linguistics courses quoted in some of the informants' statements were Old English and Translation. Exposure to Old English and Translation promote meta-linguistic awareness, whereby a foreign language learner develops the ability to reflect on the structural features of the target language. S/he further develops the conscious ability to analyse the target language and its parts to know how they are incorporated into the larger language system and hence manipulate the forms and structures of produce a vast variety of meanings (Beceren, 2010). For bilingual foreign language learners, like the informants in this study, meta-linguistics can aid their pronunciation, vocabulary, grammar and communicative and interactive abilities, which are all necessary for performing satisfactorily in the IELTS. 
Additionally, non-language or college of education courses were praised by Informant \#2 for their positive contribution to procedural knowledge, while criticized by Informant \#6. At tertiary education, general educational courses are designed to help students "acquire and practice foundational skills", "synthesize knowledge into understanding", develop and foster civic responsibility" and "apply skills beyond the classroom" (University of Stony Brook, 2012). However, in an English as a Foreign Language context like the Omani one, such courses contribute to reducing STs' target language practice opportunities. Research has shown that one of the major problems that hinders students' language proficiency development, is insufficient formal instruction time (Al-Issa, 2013).

One can thus attribute such conflicting and contradicting opinions about these courses to the practices adopted by some of the faculty members. The findings show that some faculty members adopt traditional and rigid instructional approaches such as lecturing, teacher-dominated/fronted teaching and textbookbased teaching. All these are indications of insensitivity towards STs' needs and interests and have negative implications for the development of the STs' CLP. These findings complement those reported by Peacock (2009), Coskun and Daloglu (2010).

Furthermore, other faculty members choose to avoid maximizing their STs' language practice time beyond the classroom time for different reasons, which is an indication of a lack of provision of help provided by some of those faculty members. Such findings complement those reported by Centinavci and Yavuz (2010) and Uzun (2015).

Research has shown that for candidates to succeed in the IELTS, they need to become proficient in English through possessing knowledge beyond what is found in the mandated textbook and controlled by the teacher (Al-Issa, Al-Bulushi, \& AlZadjali, 2016). This is since the development of CLP requires meaningful practice of the four language skills and involves complex learning strategies that contribute to the STs' motivation, autonomy and self-confidence (Al-Issa et al., 2016).

In conclusion, reconsidering the quality and quantity of SQU ELT courses through restructuring the program and taking into account the overall distribution of the courses and the teaching strategies, as recommended by Al-Mekhlafi (2007), can help strengthen ST's CLP in a way that would ultimately facilitate their scores in IELTS. This would also help to add systemic validity and consequential validity to the program and lead to improvement in teaching and learning, which can guarantee providing adequate language training for the program participants and achieving the aspired IELTS band score. 


\section{Limitations and Recommendations for Future Research}

Since this study adopted a qualitative approach to data analysis, quantitative methods should also be conducted, as the limitations of the qualitative studies are recognized. A broad quantitative survey has the potential to further assist to understand the informants' perspectives about the SQU ELT program construction. Furthermore, since we recruited informants with a purposeful sampling method, it was impossible to assess the difference between the students in the study and those students enrolled in the SQU ELT program.

However, regardless of the limitations found in this study, the researchers believe that the findings have added to our understanding toward the qualitative effectiveness of the ELT programs in preparing proficient STs. These perspectives need to receive attention in order to make certain progress in assisting those STs in succeeding in the IELTS, and hence, meeting the Ministry of Education's main employment condition.

\section{References and notes:}

Al-Gahtani, M. \& Reover, C. (2013). 'Hi doctor, give me handouts': Low-proficiency learners and requests. ELT Journal, 67(4), 413-424.

Al-Mekhlafi, A. (2007). The Development of Prospective EFL Teachers' Specialist Language Competencies in UAE Universities. University of Sharjah Journal for Shari'a Sciences \& Humanities, 4(1), 1-27.

Al-Issa, A. (2005). An ideological discussion of the impact of the NNESTs' English language knowledge on Omani ESL policy implementation. Asia EFL Journal On-line, 7(3). Retrieved from http://www.asian-efl-journal.com/September_05_asmai.php.

Al-Issa, A. (2013). The implications of expanding the Instruction time for the English language teaching policy implementation in the Sultanate of Oman: A qualitative study. Critical Inquiry in Language Studies, 10(4), 311-333.

Al-Issa, A. (2014). A critical examination of motivation in the Omani English language education system. Journal of Language Teaching \& Research, 5(3), 406-418. Retrieved from http://ojs.academypublisher.com/index.php/jltr/article/view/jltr0502406418.

Al-Issa, A., Al-Bulushi, A. \& Al-Zadjali, R. (2016). Arab English language candidates climbing the IELTS mountain: A Qualitatively driven hermeneutic phenomenology study. The Qualitative Report, 21(5), 848-863. Retrieved from http://nsuworks.nova.edu/cgi/viewcontent.cgi?article=2367\&context=tqr

Bachman, L., \& Palmer, A. (1996). Language Testing in Practice: Designing and Developing Useful Language Tests. Oxford: OUP.

Bozorgian, H. (2012). The relationship between listening and other language skills in international English language testing system. Theory and Practice in Language Studies, 2(4), 657-663.

Cetinavci, U. \&Yavez, A. (2010). Language proficiency level of English language teacher trainees in Turkey. The International Journal of Research in Teacher Education, 4(3), 26-54.

Cheng, L., Ren, S., \& Wang, H. (2003). Pre-service and in-service teacher education of secondary English language teachers in China. TEFL Web Journal, 2(1), 1-14.

Coskun, A. \&Daloglu, A. (2010). Evaluating an English language teacher education program through Peacock's model Australian Journalof Teacher Education, 35(6), 23-42.

Cruz, J. (2010). The role of literature and culture in English language teaching. Linguistica Aplicada, 17, 1-16.

Cullen, R. (1994). Incorporating language improvement in teacher training programs. ELT Journal, 48(2), 163171.

De Lima, D. (2001). English as a foreign language teacher training programs: An overview. Linguagem \& Ensino, 4(2), 143-153. 
Elo, S. \& Kyngas, H. (2007). The qualitative content analysis process. Journal of Advanced Nursing 62(1), 107115.

Fahmy, J. \& Bilton, L. (1992). Planning a TEFL education program: Policies, perspective and promise. ERIC Document Reproduction Service No. ED 369 281.General Education at Stony Brook. http://www.stonybrook.edu/senatecas/pdf/Gen\%20Ed\%20Final\%20Report\%20Aug\%2020,\%2020 12.pdf

Golafshani, N. (2003). Understanding reliability and validity in qualitative research. The Qualitative Report, 8(4), 597-607.

Hadjioannou, X. \& Hutchinson, M. (2010). Putting the G back in English: Preparing pre-service teachers to teach grammar. English Teaching: Practice \& Critique, 9(3), 90-105.

Hsieh, H. \& Shannon, S. (2005). Three approaches to qualitative content analysis. Qualitative Health Research, 15(9), 1277-1288.

IELTS. (2015). Information for candidates introducing IELTS to test takers. Retrieved from http://www.ielts.org/pdf/IELTS\%20Information-for-Candidates-March\%202015.pdf

Khatib, M., Ranjbar, S. \& Fat'hi, J. (2012). The role of literature in EFL classroom from an EIL perspective. Journal of Academic and Applied Studies, 2(2), 12-21.

Komur, S. (2010). Teaching knowledge and teacher competencies: A case study of Turkish preservice English teachers. Teaching Education, 21(3), 279-296.

Moates, J. (2006). Final report. Sultanate of Oman: Ministry of Education.

Morain, G. (1990). Preparing foreign language teachers: Problems and possibilities. ADEFL Bulletin, 21(2), 2024.

Palmberger, M. \& Gingrich, A. (2013). Qualitative comparative practices: Dimensions, cases and strategies. In U. Flick (Ed.), The Sage Handbook of Qualitative Data Analysis $\quad$ (pp. 94-118). London: Sage.

Pasternak, M., \& Bailey, K. M. (2004). Preparing Nonnative and Native English-Speaking Teachers: Issues of Professionalism and Proficiency. In L. D. Kamhi-Stein (Ed.), Learning and Teaching from Experience : Perspectives on Non-native English Speaking Professionals (pp. 155-175). Ann Arbor, Mich.: University of Michigan Press.

Richards, J. (2008). Second language teacher education today. RELC Journal, 39(2), 158-176.

Salihoglu, U. (2012), Pre-service teachers' and their instructors' beliefs on the effectiveness of an English language teaching education program. Procedia - Social and Behavioural Sciences, 46, 3440-3444.

Sert, O. \& Seedhouse, P. (2011). Introduction: Conversation analysis in applied linguistics. Novitas-ROYAL, 5(1), $1-14$.

Shenton, A. (2004). Strategies for ensuring trustworthiness in qualitative research projects. Education for Information, 22, 63-75.

Stern, H. (1983). Fundamental concepts of language teaching: Historical and interdisciplinary perspectives on Applied Linguistics research. Oxford: Oxford University Press.

Thiele, J. (2013). Benefits of teaching sociolinguistics. Language and Linguistics in Melanesia, 31(2), 61-69.

Tuzel, A. \& Akcan, S. (2009). Raising the language awareness of pre-service English teachers in an EFL context. European Journal of Teacher Education, 32(3), 271-287

University of Stony Brook. (2012). General Education Report. Retrieved from New York: http://www.stonybrook.edu/senatecas/pdf/Gen\%20Ed\%20Final\%20Report\%20Aug\%2020,\%2020 12.pdf

Uzun, C. (2016). Evaluation of the latest English language teacher education programme in Turkey: Teacher trainees' perspective. Cognet Education, 3, 1-16.

Van, T. (2009). The relevance of literary analysis to teaching literature in the EFL classroom.English Teaching Forum, 3, 2-9.

Wu, Y. (2013). Contrastive analysis - A discourse approach to teaching oral English skills. International Education Studies, 6(5), 87-91.

Yidirim, A. (2012). Literature and English culture in ELT. Novitas ROYAL, 6(2), 137-153.

Zhang, Y. (2009). An experimental study of the effects of listening on speaking for college students. English Language Teaching, 2(3), 194-204.

Zhang, Y., \& Wildemuth, B. (2009).Qualitative analysis of content. In B. Wildemuth (Ed.), Applications of social research methods to questions in information and library science (pp. 308-319).Westport, CT: Libraries Unlimited.

Zhanglong, M. \&Rong, Z. (2011). Comparison and model analysis between IELTS oral and CET-SET. International Conference on Education, Research and Innovation, 18, 72-76.

Acknowledgement: This study was made possible through a grant of SQU [IG/LAW/PULW/12/01]. The authors would like to express their gratitude to $S Q U$ and all the participants, who provided invaluable data for the study. 


\title{
Summary
}

\section{Close but no Cigar: Qualitative Perspectives on the English Language Content Knowledge and Methods on Communicative Language Proficiency, Implications for Succeeding in the IELTS}

\author{
Ali Al-Bulushi \\ Sultan Qaboos University, Oman \\ Ali Al-Issa
Sultan Qaboos University, Oman \\ Rima Al-Zadjali \\ Sultan Qaboos University, Oman
}

Communicative Language Proficiency (CLP) in the target language is critical for the teachers joining English language teaching for different reasons. The Ministry of Education in the Sultanate of Oman has sanctioned the score of Band 6 on the International English Language Testing System (IELTS) as the main criterion for accepting English language teachers graduating from Sultan Qaboos University (SQU). Nonetheless, some fourth-year Student Teachers (STs) have failed to achieve the specified score due to reasons pertinent to the choices made in the initial English language teacher education program content knowledge and methods. This qualitative study, hence, investigates the perspectives of purposively selected STs and faculty members about the effect of SQU English Language Teaching (ELT) content knowledge and methods on the STs' IELTS band scores. Results have shown that there is a need to reconsider the content knowledge and methods to create more opportunities for the program participants to use the language communicatively. Results have further shown that certain faculty members adopt certain teaching methods insensitive to the needs and interests of the STs and which negatively affect their CLP. The results have important implications for the STs' success in the IELTS and hence their employability.

Key words: IELTS; English Language Teaching; communicative language proficiency; content knowledge; teaching methods 